\title{
Soil moisture sensor calibration for organic soil surface layers
}

\author{
Simone Bircher ${ }^{1}$, Mie Andreasen ${ }^{2}$, Johanna Vuollet ${ }^{3}$, Juho Vehviläinen ${ }^{3}$, Kimmo Rautiainen ${ }^{3}$, François Jonard ${ }^{4,5}$, \\ Lutz Weihermüller ${ }^{4}$, Elena Zakharova ${ }^{6}$, Jean-Pierre Wigneron ${ }^{7}$, and Yann H. Kerr ${ }^{1}$ \\ ${ }^{1}$ Centre d'Etudes Spatiales de la Biosphère, Toulouse, France \\ ${ }^{2}$ Department of Geosciences and Natural Resource Management, University of Copenhagen, Copenhagen, Denmark \\ ${ }^{3}$ Finnish Meteorological Institute, Arctic Research, Helsinki, Finland \\ ${ }^{4}$ Agrosphere (IBG-3), Institute of Bio- and Geosciences, Forschungszentrum Jülich GmbH, Jülich, Germany \\ ${ }^{5}$ Earth and Life Institute, Université catholique de Louvain, Louvain-la-Neuve, Belgium \\ ${ }^{6}$ Laboratoire d'Etudes en Géophysique et Océanographie Spatiales, Toulouse, France \\ ${ }^{7}$ Division Ecologie fonctionelle et Physique de l'Environnement, Institut National de la Recherche Agronomique, \\ Bordeaux-Aquitaine, France
}

Correspondence to: Simone Bircher (simone.bircher@cesbio.cnes.fr)

Received: 30 November 2015 - Published in Geosci. Instrum. Method. Data Syst. Discuss.: 11 December 2015

Revised: 17 March 2016 - Accepted: 18 March 2016 - Published: 29 April 2016

\begin{abstract}
This paper's objective is to present generic calibration functions for organic surface layers derived for the soil moisture sensors Decagon ECH2O 5TE and Delta-T ThetaProbe ML2x, using material from northern regions, mainly from the Finnish Meteorological Institute's Arctic Research Center in Sodankylä and the study area of the Danish Center for Hydrology (HOBE). For the Decagon 5TE sensor such a function is currently not reported in the literature. Data were compared with measurements from underlying mineral soils including laboratory and field measurements. Shrinkage and charring during drying were considered. For both sensors all field and lab data showed consistent trends. For mineral layers with low soil organic matter (SOM) content the validity of the manufacturer's calibrations was demonstrated. Deviating sensor outputs in organic and mineral horizons were identified. For the Decagon 5TE, apparent relative permittivities at a given moisture content decreased for increased SOM content, which was attributed to an increase of bound water in organic materials with large specific surface areas compared to the studied mineral soils. ThetaProbe measurements from organic horizons showed stronger nonlinearity in the sensor response and signal saturation in the high-level data. The derived calibration fit functions between sensor response and volumetric water content hold for samples spanning a wide range of humus types with differing SOM characteristics. This strengthens confidence in their validity under various conditions, rendering them
\end{abstract}

highly suitable for large-scale applications in remote sensing and land surface modeling studies. Agreement between independent Decagon 5TE and ThetaProbe time series from an organic surface layer at the Sodankylä site was significantly improved when the here-proposed fit functions were used. Decagon 5TE data also well-reflected precipitation events. Thus, Decagon 5TE network data from organic surface layers at the Sodankylä and HOBE sites are based on the hereproposed natural $\log$ fit. The newly derived ThetaProbe fit functions should be used for hand-held applications only, but prove to be of value for the acquisition of instantaneous large-scale soil moisture estimates.

\section{Introduction}

The circumpolar northern colder climate zone (boreal forest and tundra) contributes with a substantial fraction to the total global land mass. Because of slower decomposition rates in these regions pronounced organic layers have been accumulating on top of the mineral soils. Particularly when frozen, organic-rich soils store a significant amount of carbon acting as important sinks. However, the higher northern latitudes are especially sensitive to climate change (IPCC, 2007) due to above-average rising temperatures (e.g., Hansen et al., 2006). Thus, a considerable positive feedback on global warming is likely once additional carbon is respired from thawing 
grounds (Stokstad, 2004). The prediction of the overall response of these ecosystems to global warming is currently highly uncertain. In this context, hydrological processes play a key role and soil moisture is one of the main factors to be assessed to understand and quantify the processes and feedback mechanisms controlling water, energy, and carbon fluxes at the land surface-atmosphere interface.

Given the particular hostility and remoteness of high latitude environments, spaceborne remote sensing techniques together with land surface modeling constitute essential tools for soil moisture observations at high temporal resolution and with complete spatial coverage (e.g., Reichle et al., 2007; Albergel et al., 2012). Nevertheless, spatially distributed in situ soil moisture measurements are indispensable for the calibration/validation (cal/val) activities of these global soil moisture products as well as in order to increase processunderstanding at local scale.

Electromagnetic-based sensors belong to the most popular in situ soil moisture measuring techniques, as they can be used for automated continuous measurements at high temporal resolution in most soil types and plant growth substrates, including shallow recordings close to the surface. Different sensor types have been developed using capacitance and impedance as well as time- or frequency-domain reflectometry and transmissometry (TDR, FDR, TDT, and FDT) methods. The shape and design of the sensors as well as the measurement and/or raw data "interpretation" is highly variable (Robinson et al., 2008). Nevertheless, they all take advantage of the large difference between the relative permittivity $(\varepsilon$; relative to free space, also referred to as dielectric constant) of dry soil and water in order to estimate the volumetric fraction of the latter (e.g., Topp, 2003; Robinson et al., 2003). $\varepsilon$ is a complex number whose real part $\varepsilon^{\prime}$ expresses energy storage based on the ability of a particle to align with the electric field. The imaginary part $\varepsilon^{\prime \prime}$ describes energy losses due to absorption and electrical conductivity. In the frequency range where most electromagnetic sensors operate the measured relative permittivities mainly correspond to $\varepsilon^{\prime}$. However, as $\varepsilon^{\prime \prime}$ contributes to a certain degree to the signal and because the observed relative permittivity is the bulk value of compound solid, gaseous, and liquid constituents, it is usually termed apparent relative permittivity $\varepsilon_{\mathrm{a}}$ (e.g., Blonquist et al., 2005).

In the case of all electromagnetic sensors, the measured raw signal of a substrate is closely related to $\varepsilon_{\mathrm{a}}$, from which the soil moisture can be derived using either dielectric mixing models or empirical calibration equations (e.g., Jones et al., 2002; Mätzler, 2006; Nagare et al., 2011). These relations are affected by the sensor design, and thus, are sensor type specific. Manufacturers generally provide default calibrations, often including both raw signal to soil moisture as well as $\varepsilon_{\mathrm{a}}$ to soil moisture relationships. Though calibrated and validated over a wide range of soil types, there is general consensus that these functions cannot hold for all conditions, and therefore, soil- and site-specific calibration is often re- quired to improve the measurement accuracy (e.g., Walker et al., 2004; Czarnomski et al., 2005; Blonquist et al., 2005; Evett et al., 2006; Dorigo et al., 2011; Mittelbach et al., 2012; Vaz et al., 2013).

Currently available impedance and capacitance sensors operate at frequencies between 20 and $300 \mathrm{MHz}$, while TDR/FDR and TDT/FDT mainly function in the GHz range (Vaz et al., 2013). The latter are generally considered more accurate with less signal contribution of $\varepsilon^{\prime \prime}$ and hence, reduced sensitivity to salinity (electrical conductivity), temperature, and soil type effects (e.g., Blonquist et al., 2005; Kelleners et al., 2005; Saito et al., 2009). However, the former are often cheaper and power consumption is lower. Given the high spatial and temporal soil moisture variability throughout scales (e.g., Western et al., 2002; Famiglietti et al., 2008), there is broad agreement concerning the benefit of increasing soil moisture network density using cheaper sensors at the cost of accuracy, in order to better represent large-scale satellite footprints and model grid cells (e.g., Czarnomski et al., 2005; Bogena et al., 2007; Kizito et al., 2008; Dorigo et al., 2011; Mittelbach et al., 2012).

While a lot of authors find manufacturers' default calibrations sufficiently accurate for various mineral soil types (apart from very clayey soils), many studies conclude that calibrations specific to organic-rich soils and humus horizons are crucial (e.g., Topp et al., 1980; Herkelrath et al., 1991; Roth et al., 1992; Paquet et al., 1993; Jones et al., 2002; Pumpanen and Ilvesniemi, 2005; Kizito et al., 2008; Sakaki et al., 2011; Vaz et al., 2013). Organic material differs from mineral by its complex structures and small bulk densities. The resulting high porosities and large specific surface areas cause the following two effects: (1) substantial water holding capacities up to $0.8-0.9 \mathrm{~cm}^{3} \mathrm{~cm}^{-3}$ compared to around $0.4-$ $0.6 \mathrm{~cm}^{3} \mathrm{~cm}^{-3}$ in the case of mineral soils (e.g., Kellner and Lundin, 2001; Li et al., 2004), and (2) a higher amount of bound water altering $\varepsilon_{\mathrm{a}}$ (Jones et al., 2002). Water molecules in the vicinity of solid surfaces are subjected to interfacial forces hindering their rotation. Consequently, their ability to align with the applied electric field (and thus, $\varepsilon$ ) is reduced. Therefore, the water layer in close proximity (several angstroms) to the solid particles exhibits a relative permittivity similar to water fixed in ice structures with $\varepsilon^{\prime} \approx 3$ (Wang and Schmugge, 1980), while in subsequent layers the value gradually approaches the one of free liquid water (Or and Wraith, 1999). Hence, the use of a calibration function for mineral soil leads to a significant underestimation of the actual moisture content in substrates like organic material with large specific surface area and thus, increased bound water fraction (e.g., Topp et al., 1980; Roth et al., 1992; Paquet et al., 1993). The relative permittivity of the dry solid particles are reported to range between 2 and 5 without a clear difference between organic and mineral substrates (e.g., Topp et al., 1980; Roth et al., 1990; Malicki et al., 1996). This lead to the assumption that $\varepsilon_{\text {solid }}$ has only little effect on $\varepsilon_{\mathrm{a}}$ (Yu et al., 1999). 
The influence of organic matter on the TDR response has been studied by many authors (e.g., Topp et al., 1980; Roth et al., 1990, 1992; Herkelrath et al., 1991; Pepin et al., 1992; Paquet et al., 1993; Malicki et al., 1996; Börner et al., 1996; Myllys and Simojoki, 1996; Schaap et al., 1996; Kellner and Lundin, 2001; Jones et al., 2002; Pumpanen and Ilvesniemi, 2005; Shibchurn et al., 2005; Nagare et al., 2011; Vasquez, 2013). However, for other electromagnetic sensors, such analyses are more scarce in the literature. Recently, Vaz et al. (2013) evaluated standard calibrations for eight electromagnetic sensors. They pointed to the rarity, and thus, necessity of further investigations on the capacitance and impedance sensor response in substrates of varying organic matter content.

At the Finnish Meteorological Institute's Arctic Research Center (FMI-ARC) in Sodankylä, northern Finland, the exploration of hydrological processes is one of the multidisciplinary key research topics. On this site there are several projects dealing with the characterization of moisture content in organic-rich soil surfaces as well as freeze-thaw characteristics using different remote sensing techniques as well as land surface modeling (e.g., Rautiainen et al., 2012, 2014; European Space Agency: ESA SMOS + Innovation Permafrost, ESA CCI Soil Moisture, ESA SMOSHiLat; National Aeronautics and Space Administration: NASA SMAP cal/val). In the Skjern River catchment in western Denmark related actions are ongoing coordinated by the Danish Center for Hydrology (HOBE). Therefore, a joined effort aimed at calibrating the used soil moisture sensors, namely, the capacitance Decagon ECH2O 5TE sensor (Decagon 5TE) ${ }^{1}$ and the impedance Delta-T ThetaProbe ML2X (ThetaProbe) ${ }^{1}$, for organic substrate. At both sites, the Decagon 5TE sensors are installed at permanent network stations (Bircher et al., 2012a; Ikonen et al., 2016) providing data to the International Soil Moisture Network (ISMN, Dorigo et al., 2011) - a global in situ soil moisture database to support validation and improvement of satellite observations and land surface models. Meanwhile, ThetaProbes are used for hand-held measurement campaigns (e.g., Bircher et al., 2012b), a current method for spatial variation studies of soil water content at different scales (e.g., Baggaley et al., 2009; Lopez-Vicente et al., 2009) and thus, frequently applied in the scope of satellite validation (e.g., Cosh et al., 2005; Kurum et al., 2012).

With the purpose of serving coarse-resolution satellite remote sensing and land surface modeling studies, the objective was to provide generic calibration functions holding for different types of organic material as encountered within the large areas under consideration. Necessarily, these functions hold a decreased degree of detail and might lack high accuracy, but will clearly outperform default calibration functions provided by the sensor manufacturers. Additionally, they should be applicable without requiring auxiliary information

\footnotetext{
${ }^{1}$ Mention of manufacturers is for the convenience of the reader only and implies no endorsement on the part of the authors.
}

for the large area of interest, such as bulk density/porosity or specific surface area/bound water fraction, as integrated in more sophisticated calibration methods (e.g., Malicki et al., 1996; Dirksen and Dasberg, 1993).

This article presents the Decagon 5TE and ThetaProbe sensor calibrations for organic soil surface layers, derived from field and laboratory measurements using soils from different locations in northern regions, mainly including the Sodankylä and HOBE network areas. While some ThetaProbe calibration efforts are present in the literature for organic material from natural soils (see Sect. 3.2), to the knowledge of the authors so far no equivalent studies have been reported in the case of the Decagon 5TE sensors. It seems that only Vaz et al. (2013) had looked into the issue for this sensor type, however, using artificial organic material in a limited water content range. Thus, the goal here was to extend the range of validity of the 5TE calibration function for a variety of natural organic substrates and create something more widely applicable.

To avoid inconsistencies, the same measurement and calibration protocol was followed at all sites. The developed fit functions were evaluated against the manufacturers' calibrations as well as earlier published fitting functions. Furthermore, soil moisture time series from both sensors collected at two Sodankylä network sites were compared, using both manufacturer's default and our own derived calibrations. Measurements from the underlying mineral soil layers with variable soil organic matter content were also considered in order to demonstrate the validity of the manufacturer calibrations within those layers.

\section{Description of study sites and data}

Figure 1 gives an overview of the soil sample locations used in this study. At the two main sites in Finland and Denmark, the Decagon 5TE and ThetaProbe responses were studied in detail. Additionally, some samples used for ThetaProbe analysis were collected in Scotland and Siberia. The soil samples used for calibration and their characteristics are listed in Table 1. It is also indicated which samples were used for laboratory and field calibrations, respectively. According to humus form classifications (Broll et al., 2006; Zanella et al., 2011), a layer is considered organic if the soil organic matter $(\mathrm{SOM})$ content is greater than $\sim 30-35 \%$. Classification of the organic samples was undertaken according to the European Humus Forms Reference Base (Zanella et al., 2011) applying a simplified three-level scheme (water regime, form, and biotype). An overview of the classified samples is shown in Table 2, which indicates that the substrates used cover a wide range of different humus types typically encountered in the higher northern latitudes.

Soil dry bulk densities range $0.05-0.4$ and $1.0-1.5 \mathrm{~g} \mathrm{~cm}^{-3}$ for the organic and mineral samples, respectively, and sand is the largest textural fraction (exceeding 80\%) in the stud- 
Table 1. Overview of the samples used for calibration. The sample name starts with the study site, followed by land cover type, soil material and indication whether used in laboratory or field calibration. O, M, F, and L denote organic, mineral, field, and lab, respectively. The letter specifying the soil material is complemented by a number if more than one sample of the same soil material is available at a given study site. $N$ is the number of sensor measurements.

\begin{tabular}{|c|c|c|c|c|c|c|c|c|c|}
\hline $\begin{array}{l}\text { Soil } \\
\text { material }\end{array}$ & Sample name & Location & $\begin{array}{l}\text { Land } \\
\text { cover }\end{array}$ & Method & $\begin{array}{l}\text { Layer } \\
\text { depth } \\
(\mathrm{cm})\end{array}$ & $\begin{array}{l}\text { SOM } \\
(\%)\end{array}$ & $\begin{array}{l}\text { Sand/silt/clay } \\
(\%)\end{array}$ & $\begin{array}{r}N \\
\text { Decagon } \\
5 \mathrm{TE}\end{array}$ & $\begin{array}{r}N \\
\text { ThetaProbe }\end{array}$ \\
\hline \multirow[t]{7}{*}{ Organic } & HOBE_Forest_O_F & Gludsted, DK & Forest & Field & $0-5$ & $69-93.0$ & $\mathrm{NaN}$ & 19 & 13 \\
\hline & HOBE_Forest_O1_L & Gludsted, DK & Forest & $\mathrm{Lab}$ & $0-5$ & 69.0 & $23.1 / 7.8 / 0.1$ & 11 & 11 \\
\hline & HOBE_Forest_O2_L & Gludsted, DK & Forest & Lab & $0-5$ & 31.0 & $66.1 / 3.3 / 0.0$ & 11 & 11 \\
\hline & HOBE_Heath_O_F & Gludsted, DK & Heath & Field & $0-5$ & $\mathrm{NaN}$ & $\mathrm{NaN}$ & 2 & 8 \\
\hline & FMI_Forest_O_L & Sodankylä, FI & Forest & Lab & $0-5$ & 36.6 & $61.7 / 1.4 / 0.3$ & 7 & 7 \\
\hline & SIB_O_L & Siberia, RU & Tundra/bog & $\mathrm{Lab}$ & $0-5$ & $\mathrm{NaN}$ & $\mathrm{NaN}$ & 0 & 3 \\
\hline & ISL_O_L & Islay, GB & Bog & Lab & $0-5$ & $\mathrm{NaN}$ & $\mathrm{NaN}$ & 0 & 17 \\
\hline \multirow[t]{5}{*}{ Mineral } & HOBE_Forest_M_L & Gludsted, DK & Forest & $\mathrm{Lab}$ & $10-15$ & 8.0 & $83.9 / 7.6 / 0.3$ & 11 & 11 \\
\hline & HOBE_Heath_M_F & Gludsted, DK & Heath & Field & $10-15$ & 15.8 & $84.7 / 13.9 / 1.4$ & 4 & 7 \\
\hline & FMI_Forest_M_L & Sodankylä, FI & Forest & $\mathrm{Lab}$ & $10-15$ & 15.1 & $84.8 / 0.2 / 0.0$ & 6 & 6 \\
\hline & FMI_Heath_M1_L & Sodankylä, FI & Heath & $\mathrm{Lab}$ & $0-5$ & 6.9 & $91.5 / 1.4 / 0.3$ & 5 & 5 \\
\hline & FMI_Heath_M2_L & Sodankylä, FI & Heath & Lab & $10-15$ & 5.0 & $92.4 / 2.6 / 0.0$ & 4 & 4 \\
\hline
\end{tabular}

Table 2. Overview over organic samples, classified according to the European Humus Forms Reference Base (Zanella et al., 2011).

\begin{tabular}{|c|c|c|c|c|c|c|c|}
\hline Location & Land cover & Water regime & Form & Biotype & Horizons & $\begin{array}{c}\text { Decagon } \\
5 \mathrm{TE}\end{array}$ & ThetaProbe \\
\hline \multirow[t]{2}{*}{ Gludsted, Denmark } & Coniferous forest & Terrestrial & Terro & Mor & OL-OF-OH & $\mathrm{x}$ & $\mathrm{x}$ \\
\hline & Heathland & Terrestrial & Terro & Moder & OL-OH & $\mathrm{x}$ & $\mathrm{x}$ \\
\hline \multirow[t]{2}{*}{ Sodankylä, Finland } & Coniferous forest & Terrestrial & Terro & Mor & OL-OF-OH & $\mathrm{x}$ & $\mathrm{x}$ \\
\hline & Heathland & Terrestrial & Enti & Mor & OL-OF-OH & $\mathrm{x}$ & $\mathrm{x}$ \\
\hline \multirow[t]{2}{*}{ West Siberia, Russia } & Tundra & Semi-terrestrial & Hydro & Hydromor & $(\mathrm{OLg})-\mathrm{OFg}-(\mathrm{OHg})$ & - & $\mathrm{x}$ \\
\hline & Bog & Semi-terrestrial & Histo & Histomor & hf & - & $\mathrm{x}$ \\
\hline Islay, Scotland, GB & Bog & Semi-terrestrial & Histo & Histomor & hf-hm & - & $\mathrm{x}$ \\
\hline
\end{tabular}

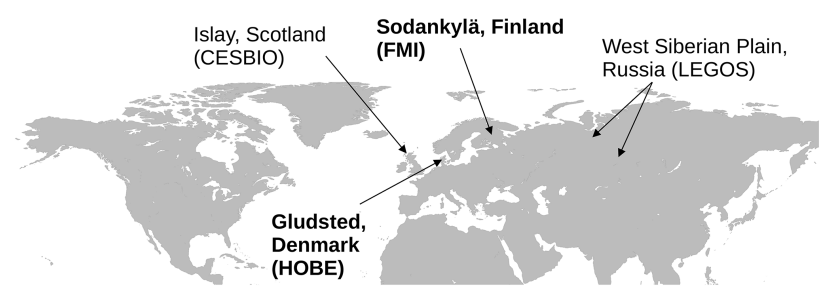

Figure 1. Overview over all sampling locations (main study sites are in bolt).

ied mineral soils. Decagon 5TE electrical conductivity measurements of all sites remain low with values in the range between 0.00 and $0.13 \mathrm{~d} \mathrm{Sm}^{-1}$.

In the following, the different sites, including the collected samples and data, are described in detail.

\subsection{Arctic Research Center, Sodankylä, Finland (FMI)}

The FMI-ARC is situated in Sodankylä $\left(67.368^{\circ} \mathrm{N}\right.$, $26.633^{\circ} \mathrm{E}$ ) in the boreal forest of northern Finland intermixed with heathland, bogs, and open water (e.g., Rautiainen et al., 2012; Ikonen et al., 2016). The prevailing soil type in aerated zones is podsol of mainly very sandy texture and overlying organic surface layers. A soil moisture and soil temperature network (Ikonen et al., 2016) is distributed in different land cover and soil types around the Sodankylä Research Center Decagon 5TE Sensors were placed at 5, 10, 20,40, and $80 \mathrm{~cm}$ depths, whereby the top layers (5 and $10 \mathrm{~cm}$ depth) hold three sensors each. Calibration samples were collected from two stations. At the station within a coniferous forest ("UG Forest 1") one sample was taken from the organic surface layer along with one sample from the underlying sandy A horizon. At the station in heathland located within a forest clearing ("HA Open 1"), a pronounced organic surface layer is absent and samples were excavated from the sandy A horizon.

Around the same two stations spatial soil moisture variability had been assessed during summer 2012 by means of ThetaProbe measurements. For 20 days within a 3-month period (June-August 2012), these measurements were taken from the surface in a hand-held fashion. As they were not 
Table 3. Soil moisture sensor characteristics from manufacturer manuals as well as findings of Vaz et al. (2013).

\begin{tabular}{|c|c|c|c|c|c|c|c|c|}
\hline \multirow[t]{2}{*}{ Sensor } & \multirow[t]{2}{*}{ Type } & \multirow[t]{2}{*}{$\begin{array}{r}\text { Frequency } \\
(\mathrm{MHz})\end{array}$} & \multirow[t]{2}{*}{$\begin{array}{l}\text { Output } \\
\text { type }\end{array}$} & \multirow{2}{*}{$\begin{array}{l}\text { Length of } \\
\text { prongs } \\
(\mathrm{cm})\end{array}$} & \multicolumn{2}{|c|}{$\begin{array}{l}\text { Sampling diameter (of } \\
\text { influence) }(\mathrm{cm})\end{array}$} & \multicolumn{2}{|c|}{$\begin{array}{l}\text { Soil moisture accuracy (factory } \\
\text { calibration mineral) }\left(\mathrm{cm}^{3} \mathrm{~cm}^{-3}\right)\end{array}$} \\
\hline & & & & & Manufacturer & $\begin{array}{l}\text { Vaz et } \\
\text { al. (2013) }\end{array}$ & Manufacturer & $\begin{array}{l}\text { Vaz et } \\
\text { al. }(2013)\end{array}$ \\
\hline $\begin{array}{l}\text { Decagon } \\
\text { ECH2O 5TE }\end{array}$ & Capacitance & 70 & $\begin{array}{l}\text { Raw } \\
\left(=50 \varepsilon_{\mathrm{a}}\right)\end{array}$ & 5.2 & 8.6 & 4.4 & $\begin{array}{l}0.030 \\
\text { (Topp et al., 1980) }\end{array}$ & 0.040 \\
\hline $\begin{array}{l}\text { Delta-T } \\
\text { ThetaProbe } \\
\text { ML2x }\end{array}$ & Impedance & 100 & Voltage & 6.0 & 4.0 & 2.0 & 0.050 & 0.029 \\
\hline
\end{tabular}

involved in the calibration process these data served for validation in this study.

\subsection{Gludsted plantation, Denmark (HOBE)}

The Danish site is situated in the Skjern River catchment in western Denmark and has been intensely investigated in the framework of HOBE (Jensen and Illangasekare, 2011). Soil samples were collected within the Gludsted spruce plantation $\left(56.074^{\circ} \mathrm{N}, 9.334^{\circ} \mathrm{E}\right)$ in forested parts as well as heathland. The naturally occurring soil type is a podsol of coarse sandy texture with pronounced organic surface layers. Soil moisture and soil temperature measurement stations, part of a spatially distributed network (Bircher et al., 2012a; Andreasen et al., 2016), are installed in the forest with Decagon 5TE sensors at 5,25 , and $55 \mathrm{~cm}$ depths of the mineral soil as well as in the overlying organic layer. The samples used for laboratory calibration were taken from organic surface layers in the vicinity of two forest network stations. Additionally, at one of the two stations a sample from the underlying mineral A horizon was collected. At this location a field calibration experiment (Sect. 4.2) took place. The resulting series of field data measured in organic horizons also include some Decagon 5TE-ThetaProbe-gravimetric sample couples collected around other Decagon forest stations, taken in the scope of cosmic-ray neutron detector calibration (Andreasen et al., 2016). In order to further increase the number of field calibration points some measurements acquired during a remote sensing cal/val campaign in 2013 (Jonard et al., 2014) were added to the database. This includes samples from the organic surface layer as well as the underlying sandy A horizon of a heathland soil (Gludsted Plantation, Denmark) measured by means of Decagon 5TE sensors, ThetaProbes, and gravimetric samples.

\subsection{Additional organic samples}

In fall 2013, the Centre d'Etudes Spatiales de la Biosphère (CESBIO), Toulouse, collected peat samples in two neighboring bogs on the Island Islay in western Scotland $\left(55.743^{\circ} \mathrm{N}, 6.178^{\circ} \mathrm{W}\right)$. Additionally, the Laboratoire
d'Etudes en Géophysique et Océanographie Spatiales (LEGOS), Toulouse, provided organic samples taken on the West Siberian Plain during their field campaigns from a tundra area in summer $2012\left(65.910^{\circ} \mathrm{N}, 74.659^{\circ} \mathrm{E}\right)$ and a bog in summer $2013\left(56.941^{\circ} \mathrm{N}, 82.607^{\circ} \mathrm{E}\right)$.

\section{Soil moisture sensors}

\subsection{Decagon ECH2O 5TE}

The Decagon ECH2O 5TE sensor is based on the capacitance method to measure the medium around three $5.2 \mathrm{~cm}$-long prongs at $70 \mathrm{MHz}$ frequency (Decagon Devices Inc., 2014). The plastic-coated sensor head is sensitive to the surrounding permittivity and thus, should be completely covered by the medium. When using a Decagon Em50 digital/analog data $\operatorname{logger}, \varepsilon_{\mathrm{a}}$ can be estimated dividing the raw sensor output by 50 . By default, the Topp equation for mineral soils (Topp et al., 1980) is used to calculate soil moisture. In addition, the probe also provides temperature and electrical conductivity measurements. The Decagon 5TE sensor as well as its predecessor TE have been tested in several studies (e.g., Kizito et al., 2008; Saito et al., 2009; Assouline et al., 2010; Rosenbaum et al., 2010, 2011; Sakaki et al., 2011; Varble and Chavez, 2011; Ganjegunte et al., 2012; Vaz et al., 2013). To our knowledge, only one calibration curve for organic material has previously been reported. However, this function developed by Vaz et al. (2013) is based on a sample from an artificial organic plant potting mix and was never tested in organic material from a natural soil horizon. It was only calibrated up to a water content of $\sim 0.35 \mathrm{~m}^{3} \mathrm{~m}^{-3}$ and without burying the sensor head in the material.

Some of the probe's characteristics are listed in Table 3, including information from the manufacturer manual as well as findings by Vaz et al. (2013). Soil moisture accuracy in mineral soils is around $0.03-0.04 \mathrm{~cm}^{3} \mathrm{~cm}^{-3}$ (applying the Topp equation), and the diameter of the probe's sensitivity lies in the range of approximately $4-8 \mathrm{~cm}$. In the framework of HOBE, the Decagon 5TE sensor has been previously evaluated for near-surface sandy soil layers in the Skjern River 
catchment. Using Topp's equation, both Vasquez and Thomsen (2010) and Bircher et al. (2012a) independently found the sensor to be accurate within $\pm 0.02-0.03 \mathrm{~cm}^{3} \mathrm{~cm}^{-3}$ under coniferous forest, heathland, as well as in agricultural fields.

\subsection{Delta-T ThetaProbe ML2x}

The Delta-T ThetaProbe ML2x is a soil moisture sensor with four $6 \mathrm{~cm}$-long steel rods building an array whose impedance varies with the moisture content of the measured medium (Delta-T Devices Ltd., 1999). The corresponding voltage output $\mathrm{V}$ at $100 \mathrm{MHz}$ can be converted into the soil's apparent relative permittivity, using $\sqrt{\varepsilon_{\mathrm{a}}}=1.07+6.4 \mathrm{~V}-6.4 \mathrm{~V}^{2}+4.7 \mathrm{~V}^{3}$ (Gaskin and Miller, 1996). $\varepsilon_{\mathrm{a}}$ can then be related to moisture content using the manufacturer's calibrations for mineral and organic substrates. The probe has been evaluated in different studies and calibration functions are already reported for a range of natural organic substrates (e.g., Kurum et al., 2012; Overduin et al., 2005; Yoshikawa et al., 2004), and artificial potting/compost substrates (e.g., Nemali et al., 2007; Kargas and Kerkides, 2008; Kang et al., 2010; Vaz et al., 2013). Major probe characteristics are listed in Table 3. Soil moisture accuracy in mineral soils is around $0.03-0.05 \mathrm{~cm}^{3} \mathrm{~cm}^{-3}$ (applying factory-supplied calibration), and the diameter of the probe's sensitivity lies in the range of approximately $2-4 \mathrm{~cm}$.

\section{Method}

\subsection{Laboratory calibration measurements}

Laboratory sensor calibrations for the organic and mineral substrates collected in Finland and Denmark (Sects. 2.1 and 2.2) were carried out at the respective institutions, following the same protocol. As organic material can be strongly affected by shrinkage during drying (e.g., Schaap et al., 1996; Pumpanen and Ilvesniemi, 2005), a significant error might occur when assuming a constant bulk density over the entire water content range. To avoid this issue the material was initially saturated and the changing volume and bulk density during the subsequent dry down were automatically accounted for. The saturated bulk densities of the respective soils were previously estimated from field samples and the collected saturated material was packed accordingly into large buckets. In the center of each bucket one Decagon 5TE sensor was installed permanently at the surface. The sensors were always placed in horizontal position with the blades in a vertical direction in order to avoid ponding of water. Distances to the bucket borders were clearly larger than the maximum diameter of the probe's sensitivity (Table 3). The Decagon 5TE readings were logged continuously, while ThetaProbe measurements and gravimetric samples were taken from the surface at defined times. A lot of attention was paid to proper application of the ThetaProbes: the four rods of the instrument were inserted vertically and pushed firmly into the substrate in order to assure good contact and avoid air gaps, and yet careful not to compress the material too much. This is common practice with this sensor type, in the case of organic material, for example, applied by Nemali et al. (2007), Kargas and Kerkdis (2008), and Vaz et al. (2013) in the laboratory as well as by Kurum et al. (2012) in the field. In our case, three readings were taken at a given time step in order to check the repeatability of the measurements, while the mean was recorded each time. Additionally, one reference sample was extracted per time step using steel rings of known volume. As buckets were of large sizes, enough material for all the gravimetric samples was available without disturbing the sensor measurements and no backfilling of material was necessary. The samples were oven dried at $105^{\circ} \mathrm{C}$ for $24 \mathrm{~h}$ for the mineral soils and at $85^{\circ} \mathrm{C}$ for $48 \mathrm{~h}$ for the organic material as, for example, practiced by Nagare et al. (2011). O'Kelly (2004) had found that around this temperature, mass loss due to charring balanced the effects of residual water caused by the strong water-binding capacities of organic matter. Subsequently, the estimated gravimetric moisture contents were converted into volumetric moisture contents by the knowledge of the bulk density. Soil texture and organic carbon were determined using standard procedures (sieving as well as using a Malvern Mastersizer 2000 and loss on ignition).

The samples from organic surface horizons in Siberia and Scotland (Sect. 2.3) were handled at CESBIO, France. They were not large enough to place Decagon 5TE sensors. Thus, only ThetaProbe readings (in triplicates) and respective gravimetric samples were taken.

\subsection{Field calibration measurements}

During the field calibration experiment in the vicinity of one Danish forest network station (see Sect. 2.2), a Decagon 5TE sensor was installed in the organic horizon and logged continuously. After the first measurements of extremely dry conditions in summer 2013, the soil was saturated. During the drying period, three ThetaProbe readings and gravimetric samples were acquired and averaged for each measurement in time. In the case of these data and all additional field observations used in this study (Decagon 5TE-ThetaProbegravimetric sample couples described in Sect. 2.2), sensor installation, measurement, and drying protocols were identical to the ones described above for the laboratory calibration.

\subsection{Fitting of calibration functions and validation}

All field and laboratory data were gathered and sensor output was plotted against volumetric moisture content for Decagon 5TE-ThetaProbe and organic-mineral samples, respectively. In the case of continuously logged Decagon 5TE data, the two measurements closest to each ThetaProbe/sample timestamp were extracted and averaged. The resulting number of available data points per site and 
sensor type is indicated in Table 1. Sensor calibrations based on our measurements were carried out for the ensemble of data measured in the organic horizons of all studied sites, while for the data from underlying mineral soil layers the validity of the manufacturer calibrations was tested. Calibration curves were fitted through the data using mathematical descriptions already reported in the literature on soil moisture sensor calibration. The fitted functions were compared with corresponding manufacturer calibration curves as well as calibrations reported in the literature (specified in Sect. 5.3, Table 6, Fig. 4).

To further validate the proposed fit functions, Decagon 5TE and ThetaProbe soil moisture time series from the forest ("UG Forest 1") and heathland ("HA Open 1") network stations in Sodankylä recorded during summer 2012 (see Sect. 2.1) and not used in the calibration process were compared to test whether the soil moisture from the two sensor types agreed. At both sites, one of the three Decagon 5TE sensors at $5 \mathrm{~cm}$ depth was chosen for this study together with the ThetaProbe surface data sampled in the immediate vicinity. The five ThetaProbe values available per day were averaged for our purpose. In the case of the Decagon 5TE data the two time steps closest to the mean ThetaProbe acquisition time were averaged, resulting in maximum time shift between the two measurements of less than $30 \mathrm{~min}$. For the organic surface layer at the "UG Forest 1" site soil moisture estimates using manufacturer default calibrations as well as newly derived fit functions were compared. Thereby, the ThetaProbe "organic" default function was chosen, while for the Decagon 5TE sensor the only available Topp et al. (1980) equation for mineral soils was applied. For the low organic mineral surface soil at the "HA Open 1" site default functions for mineral soils provided by the manufacturers were considered. To get a better insight into the temporal evolution of the soil moisture pattern over time, hourly rainfall intensities $\left(\mathrm{R} \_1 \mathrm{H}\right)$ measured at Tähtelä at the center of the Sodankylä research area $(\sim 0.5$ and $2.5 \mathrm{~km}$ distance from the "HA Open 1 " and "UG Forest 1" network stations) were plotted.

For the statistical analysis throughout our study the Pearson's correlation coefficient $(R)$, bias (mean difference between excepted and measured values), and bias-corrected root mean square deviation (RMSD) were computed.

\section{Results and discussion}

\subsection{Sensor output - volumetric moisture content response}

Figure 2 depicts the Decagon 5TE and ThetaProbe output ( $\varepsilon_{\mathrm{a}}$ and voltage, respectively) separately plotted against the volumetric moisture content for the studied organic $(>30 \%$ SOM, top row panels) and mineral soil horizons $(<30 \%$ SOM, bottom row panels). The corresponding manufac-
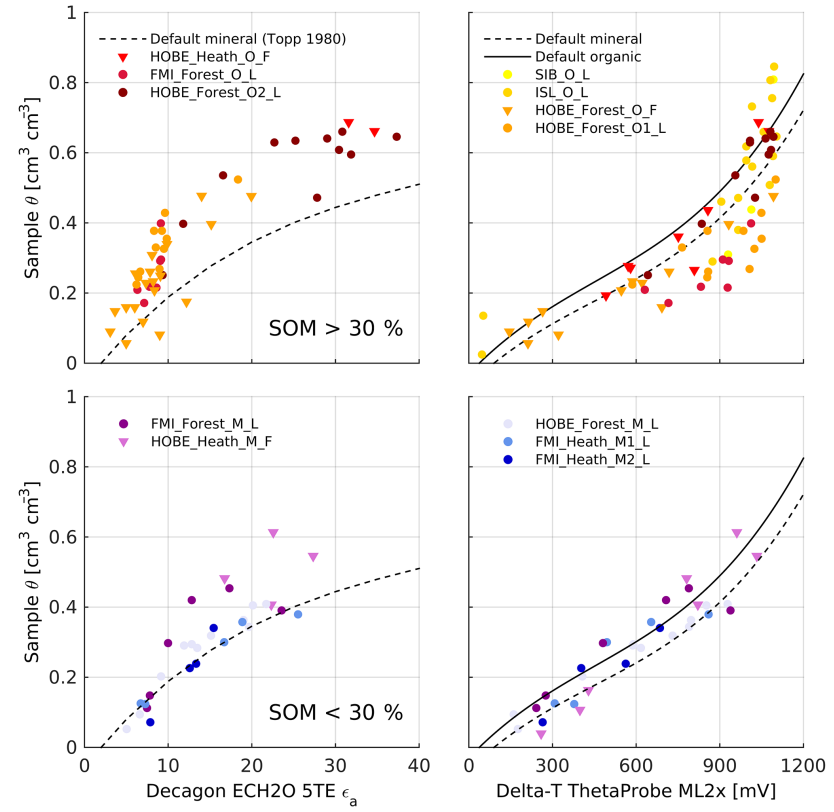

Figure 2. Decagon 5TE apparent relative permittivity $\varepsilon_{\mathrm{a}}$ (left panels) and ThetaProbe voltage $(\mathrm{mV})$ (right column panels) against volumetric moisture content $\theta$ for organic $(\mathrm{SOM}>30 \%$, top row panels) and mineral soil horizons ( $\mathrm{SOM}<30 \%$, bottom row panels), laboratory $\bullet$ and field $\boldsymbol{\nabla}$ data, with color codes from highest to lowest SOM content (yellow-dark red and purple-dark blue, respectively). For mineral horizons, blue and purple signatures mean $\mathrm{SOM}<10$ and $>10 \%$, respectively. Manufacturer's default calibration curves (black dashed and continuous lines) are also included. Regarding the specifications of sample names and respective SOM fractions, please see Table 1.

turer calibration curves are depicted as well (continuous and dashed black lines for organic and mineral, respectively). Additionally, points were color coded to distinguish between SOM contents (yellow-red and blue-purple for organic and mineral, respectively; see Table 1 for SOM contents of the respective samples), while data obtained from laboratory and field measurements are discriminated by different symbol types (dots and triangles, respectively).

For both sensor types, the field measurements (triangles) are in good agreement with the laboratory data (dots). For the mineral soils with a SOM content below $10 \%$ (blue colors) both Decagon 5TE and ThetaProbe data scatter around the respective manufacturer calibration curves, and thus, demonstrate the validity of the latter. In the case of the Decagon 5TE sensor this underlines earlier results by Vasquez and Thomsen (2010) and Bircher et al. (2012a) who also found the sensor to be accurate within $\pm 0.02-0.03 \mathrm{~cm}^{3} \mathrm{~cm}^{-3}$ in sandy A horizons with low organic matter contents using the default Topp's equation.

In contrast, for the mineral samples with a SOM exceeding $10 \%$ (purple colors) the trends in the data differ for both sensor types. While for the ThetaProbe (right column) the 
data of increased SOM content show a behavior comparable to the measurements in mineral soils with $\mathrm{SOM}<10 \%$, in the respective Decagon 5TE data (left column) a clear tendency towards a decrease in apparent relative permittivities at given moisture contents can be observed. For the measurements in the organic horizons ( $>30 \%$ SOM, yellow-red colors), this trend of decreasing $\varepsilon_{\mathrm{a}}$ for a given moisture content with increasing SOM content is even more distinct, and despite the scatter, consistent in the data measured throughout a range of humus types from different locations. Especially at higher moisture contents a more or less constant offset is detectable, while below $\sim 0.4 \mathrm{~cm}^{3} \mathrm{~cm}^{-3}$ an increase in curvature is observable, indicating only a small change in $\varepsilon_{\mathrm{a}}$ for a relatively large change in soil moisture. This behavior is in good agreement with observations from TDR readings (e.g., Topp et al., 1980; Roth et al., 1992; Paquet et al., 1993; Kellner and Lundin, 2001; Jones et al., 2002), and can be explained by the substantial fraction of bound water on the large specific surface area of the organic material. Considerable amounts of rotationally hindered water molecules result in the recording of lower apparent relative permittivities for organic-rich materials compared to low organic mineral soils for the same water content. Adsorption forces decrease exponentially with increasing distance to the solid surface. At low water contents where first layers affected by binding forces closest to solid surfaces are filled, an increase in moisture content barely increases $\varepsilon_{\mathrm{a}}$. Once these layers are filled, a further increase in moisture level results in a more rapid rise of $\varepsilon_{\mathrm{a}}$. Hence, the offset compared to the sensor response in mineral soils of low SOM content becomes constant. The value of $10 \%$ SOM (blue colors $<10 \%$ SOM $>$ purple colors) as threshold for the appearance of bound water effects is in accordance with findings reported by Paquet et al. (1993), Vaz et al. (2013), and Vasquez (2013). Hence, these data suggest that if more such Decagon 5TE readings were collected in the future, an attempt could be made to derive a calibration law for mineral horizons as a function of intermediate SOM content $(10-30 \%)$. In purely organic horizons, bound water effects are most pronounced, whereby, above $30 \%$ SOM content (yellow-red colors) the dependency of the magnitude of bound water effects on the SOM content seems to level off, meaning that no further decrease of $\varepsilon_{\mathrm{a}}$ with augmenting soil organic matter is clearly detectable.

The ThetaProbe data (right column panels) for the organic soil layers (top row panels) again show scatter but with a clear trend irrespectively of the sample location or humus type. However, in contrast to the Decagon 5TE data (left column, top row panels), there is a closer match between our soil moisture measurements and soil moisture computed based on the default calibrations for mineral and organic substrates. It is worth noting that there is only a small difference in the soil moisture estimation between the two default calibration curves whilst their shape remains consistent. Nevertheless, in the medium to high range of the sensor outputs (600$1000 \mathrm{mV}$ ) for the organic samples the default curves are not able to reproduce our measurements due to more pronounced curvature in our data. This results in (1) a tendency towards increased sensor output at a given moisture content compared to both default curves in the middle range, and (2) saturation in the sensor's response around $1000 \mathrm{mV}$.

In conclusion, one can state that for both sensor types deviating sensor outputs in the case of measurements conducted in organic horizons (yellow-red colors) compared to mineral layers with low SOM content (blue colors) are clearly demonstrated. The scatter in the data from organic horizons is in comparable range as reported for similar calibration studies using TDR sensors (e.g., Schaap et al., 1996; Kellner and Lundin, 2001; Pumpanen and Ilvesniemi, 2005; Nagare et al., 2011). Thereby, the spread is always higher for organic substrates compared to mineral soils due to the complex nature (i.e., very high porosities and large specific surface areas) of the former. However, no distinct differences in measurements' behavior from samples ranging a variety of humus types and acquired by different users are noticeable. Based on this first analysis it can be hypothesized that for each sensor type one calibration function should hold for reliable estimates of the moisture content in organic surface horizons (> $30 \% \mathrm{SOM}$ ) of different characteristics and variable SOM. In the following, the presented results and discussion will concentrate on this subject.

\subsection{Curve fits for organic material}

Figure 3 illustrates the calibration curves fitted through the data measured in the different organic soil layers (black circles). For the Decagon 5TE sensor data pairs of apparent relative permittivity readings and corresponding volumetric moisture contents (left column panels) different functions were tested: third-order polynomial (dark blue), power (light blue), natural logarithm (red), and square root (orange). With respect to the ThetaProbe (right column panels), fit functions (red) were derived for both output voltage-volumetric moisture and apparent relative permittivity-volumetric moisture pairs, (third- and first-order polynomial in top and bottom row, respectively), as they are equally used in many studies. For comparison, manufacturer calibration curves are also included in the plots (continuous and dashed black lines in the case of curves for organic and mineral materials, respectively). All functions shown in Fig. 3 are listed in Table 4 and the corresponding fitting statistics are presented in Table 5.

For the Decagon 5TE sensor, the statistics show no clear difference between the different tested fit functions. Compared to the manufacturer calibration all of them result in a significantly decreased bias and an improved RMSD while $R$ remains unchanged. Based on a visual inspection in Fig. 3 (left column panels) the natural logarithmic fit seems to most closely follow the measured data with a more pronounced curvature at low moisture contents up to about $0.2 \mathrm{~cm}^{3} \mathrm{~cm}^{-3}$, and a similar curvature as the mineral default function for higher moisture contents. 

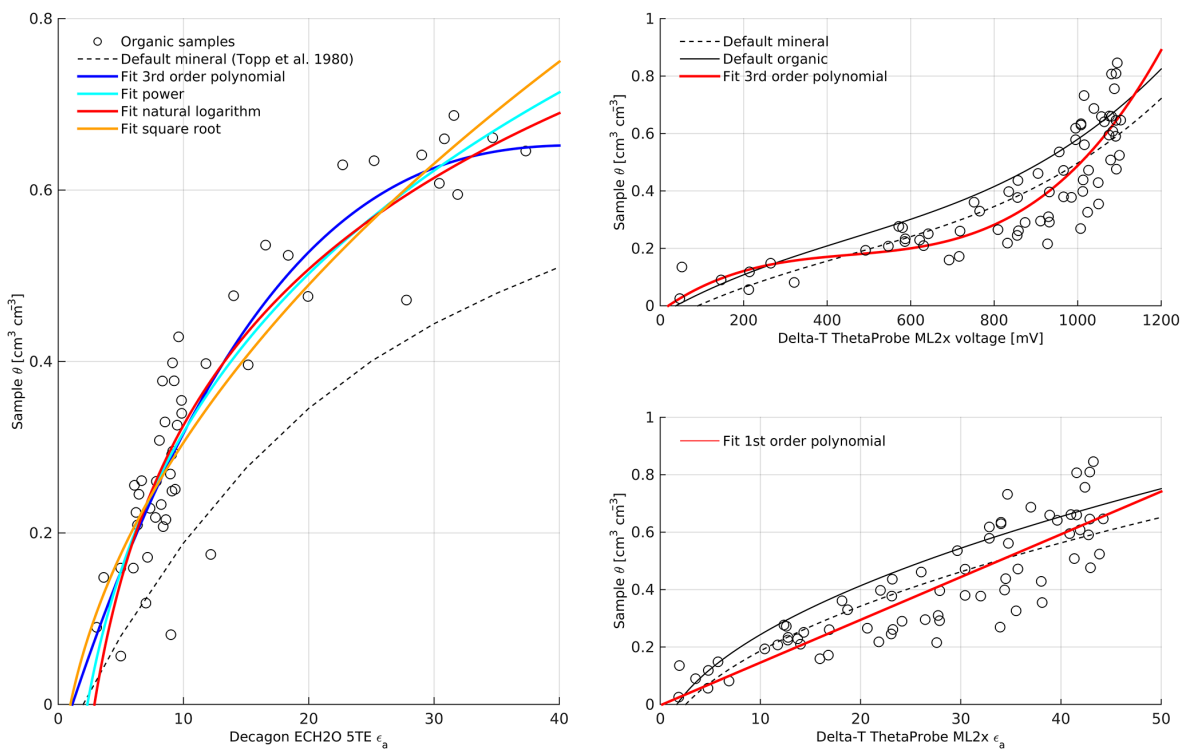

Figure 3. Fitting functions for the Decagon 5TE apparent relative permittivity $\varepsilon_{\mathrm{a}}$ (left panels), and ThetaProbe voltage (mV) (upper right panel) as well as $\varepsilon_{\mathrm{a}}$ (lower right panel) against volumetric moisture content $\theta$ including manufacturer's default calibration curves for the organic soil layers $(\mathrm{SOM}>30 \%)$.

For the ThetaProbe the third-order polynomial fit between the sensors millivolt $(\mathrm{mV})$ output and the measured soil moisture (right column, top row panels) shows a similar curve shape as the default functions for mineral and organic substrates, but with the aforementioned increased curvature. Meanwhile, a steeper slope compared to the quasi-linear default curves becomes apparent in the case of the first-order polynomial fit through the $\varepsilon_{\mathrm{a}}$-moisture content couples (right column, bottom row panels). For both new functions (mVmoisture content and $\varepsilon_{\mathrm{a}}$-moisture content), the $R$ and RMSD improved slightly, whereas the bias stayed in the order of the default function for mineral soils, which is clearly lower than for the default function for organic materials.

\subsection{Comparison of fitted versus the literature calibrations for organic materials}

Figure 4 displays the functions fitted (red curves) to the measurements performed on our organic samples (only the selected logarithmic function for Decagon 5TE) together with petrophysical or empirical relationships for organic samples taken from the literature. In the case of the Decagon 5TE sensor (left column) this includes the calibration for an organic plant potting mix reported by Vaz et al. (2013) for the same sensor type (orange line) as well as the following calibration laws for organic samples obtained from TDR measurements (blue and green lines): Pepin et al. (1992), Roth et al. (1992), Paquet et al. (1993), Malicki et al. (1996) using a bulk density of $0.1 \mathrm{~g} \mathrm{~cm}^{-3}$, Schaap et al. (1996), Kellner and Lundin (2001), Yoshikawa et al. (2004) for living sphagnum, and Pumpanen and Ilvesniemi (2005). Concern- ing the ThetaProbe (right column panels), only functions derived for organic soil layers with the same sensor type were selected, namely those of Nemali et al. (2007), Kurum et al. (2012) for an OL layer using a bulk density of $0.1 \mathrm{~g} \mathrm{~cm}^{-3}$, and Vaz et al. (2013) for the relationship between $\mathrm{mV}$ output and moisture content (wine red, dark red, and orange lines in top row panels), and Yoshikawa et al. (2004, living sphagnum) as well as Kargas and Kerkides (2008) for the relationship between $\varepsilon_{\mathrm{a}}$ and moisture content (beige and yellow lines in bottom row panels), respectively. Manufacturer calibration curves are also included in the plots (continuous and dashed black lines in the case of curves for organic and mineral materials, respectively). Corresponding statistics are listed in Table 6.

The natural $\log$ fit through the Decagon 5TE data (left column panels, red line) and the calibration proposed by Vaz et al. (2013) applied to the respective data (left column, orange line) exhibit a similar $R$ value, while both RMSD and bias increased for the latter. The two curves follow each other closely within the calibration range of Vaz et al. (2013), while they deviate beyond a water content of $\sim 0.5 \mathrm{~cm}^{3} \mathrm{~cm}^{-3}$ due to a more pronounced curvature of our natural $\log$ fit. Good agreement within the calibrated range of two curves derived from different natural organic horizons and a plant potting mix further strengthens confidence that the type and structure of organic material does not drastically affect the measurements themselves. And the same seems to account for the application with or without burying the sensor head in the materials, as practiced in this work and by Vaz et al. (2013), respectively. This adds a further point of validity, making the here-derived function even more generally applicable. 

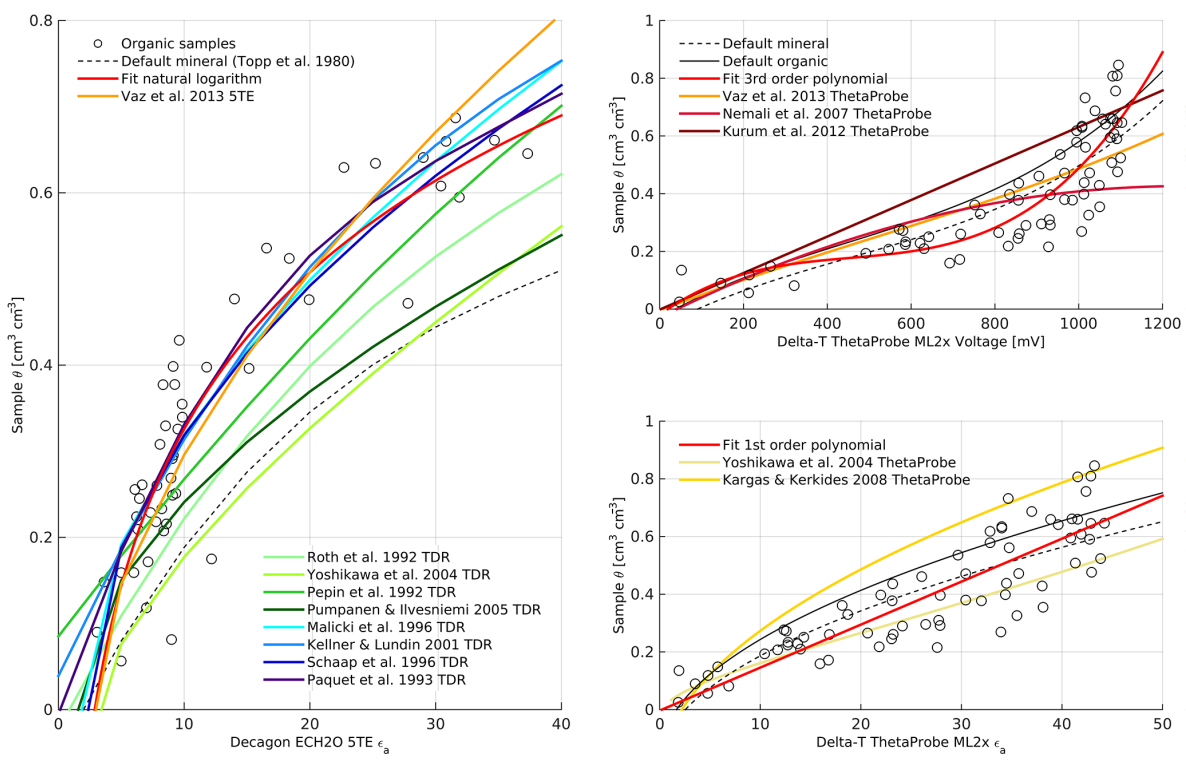

Figure 4. Comparison between reported petrophysical and empirical relationships applied to our data measured in organic soil layers for the Decagon 5TE apparent relative permittivity $\varepsilon_{\mathrm{a}}$ (left panel), and ThetaProbe voltage (mV) (upper right panel) as well as $\varepsilon_{\mathrm{a}}($ lower right panel) against volumetric moisture content $\theta$ including respective manufacturer's default calibration curves and best fits.

For the functions derived from TDR measurements in organic soil layers $R$ values also stayed in the same order as for our functions fitted through the Decagon 5TE data (left column panels). Compared to our best suited function (natural log fit, red line) the ones proposed by Paquet et al. (1993), Schaap et al. (1996), Kellner and Lundin (2001), and Malicki et al. (1996) using a bulk density of $0.1 \mathrm{~cm}^{3} \mathrm{~cm}^{-3}$ (curves in blue colors), lie in the same range with very similar RMSD, and small (though some order of magnitudes larger) bias of around $\pm 0.01 \mathrm{~cm}^{3} \mathrm{~cm}^{-3}$. Furthermore, the curvatures of these functions are slightly less pronounced either in the dry or wet range. Other functions (curves in green colors) are clearly offset with mostly larger RMSD, significantly larger bias (above $0.03 \mathrm{~cm}^{3} \mathrm{~cm}^{-3}$ ) and less curvature (Pepin et al., 1992; Roth et al., 1992; Yoshikawa et al., 2004; Pumpanen and Ilvesniemi, 2005). While the absolute match between the calibration curves for organic material of the Decagon 5TE sensor and the TDR-based ones is not always good, it is still worth noting that they all show the same general curve shape. The discrepancies between these different calibration laws presumably arise from the different sensor designs, measurement principles, and measurement frequencies used as also pointed out by Vaz et al. (2013).

For the ThetaProbe $\mathrm{mV}$ versus moisture content relationship (right column, top row) all considered calibrations show very similar behavior as the default calibrations (black lines) up to $\sim 0.2 \mathrm{~cm}^{3} \mathrm{~cm}^{-3}$. However, at higher moisture contents the curves start deviating significantly without a clear pattern. Like our third-order polynomial fit (red line) the function reported by Vaz et al. (2013, orange line) exhibits the same type of shape as the default functions though with weaker cur- vature. Meanwhile, the Nemali et al. (2007, wine red line) and Kurum et al. (2012, dark red line) functions show differing characteristics. In any case, the statistics in terms of all measures clearly deteriorate when applying other calibration laws to our data. The Nemali et al. (2007) curve and our fit function were calibrated even for high moisture contents $\left(0.8-0.9 \mathrm{~cm}^{3} \mathrm{~cm}^{-3}\right)$, while the Vaz et al. (2013) and Kurum et al. (2012) fits were derived only for low to moderate moisture contents up to $0.3-0.35 \mathrm{~cm}^{3} \mathrm{~cm}^{-3}$.

In the case of the ThetaProbe $\varepsilon_{\mathrm{a}}$ versus moisture content calibration (right column, bottom row panels), all included calibration laws perform similarly well in terms of $R$, while those of Kargas and Kerkides (2008, yellow line) and Yoshikawa et al. (2004, beige line) showed increased RMSDs and biases (with opposite signs for the two specified functions). The Kargas and Kerkides (2008) curve (calibrated up to $0.75 \mathrm{~cm}^{3} \mathrm{~cm}^{-3}$ ) exhibit a shape similar to the default curves though with lower $\varepsilon_{\mathrm{a}}$ at a given moisture content. Yoshikawa et al. (2004) show a more analog trend to our data with larger $\varepsilon_{\mathrm{a}}$ for a given moisture content compared to the mineral default curve and deviation starts above $0.3 \mathrm{~cm}^{3} \mathrm{~cm}^{-3}$ beyond the Yoshikawa et al. (2004) calibration range.

The presented results indicate that for the ThetaProbe data a clear consistency between measurements, fitted functions, theory, and the literature calibrations is lacking. As practiced in our experimental setup, Nemali et al. (2007), Kurum et al. (2012), and Vaz et al. (2013) also removed and reinserted the ThetaProbe after each measurement, while in the studies by Yoshikawa et al. (2004) and Kargas and Kerkidis (2008) probes remained installed throughout the entire experiments. 


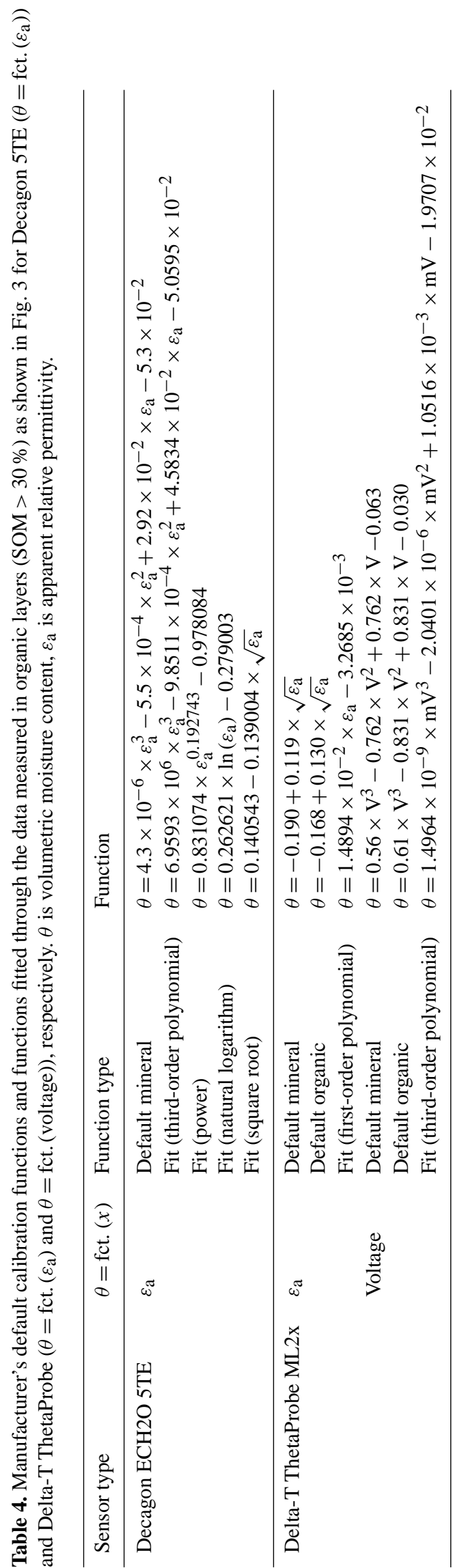

Certainly, a hand-held application with slightly changed sampling location each time results in increased data variability compared to permanently installed probes, the effect being more pronounced in organic substrate of complex structure compared to more homogeneously distributed mineral soils. However, irrespectively of the two approaches used, no clear difference is detectable in the functions' curve shapes. Another plausible explanation for the nonuniform behavior could be the ThetaProbe's rod configuration that significantly concentrates the electromagnetic field around the central electrode, resulting in a small sampling volume (Table 3 ). This drawback was already raised by Robinson et al. (1999) and Vaz et al. (2013) who stated that this possibly renders the measurements more sensitive to compaction during the insertion of the instrument, as the effect is most distinct around the probe's center. Additionally, this problem becomes more important as moisture content increases. This would explain why the agreement between different calibration curves is best at very small water contents and deteriorates more and more towards high soil moisture values.

\subsection{Comparison of soil moisture time series at two Sodankylä network sites}

Figure 5 shows the comparison of average ThetaProbe and Decagon 5TE soil moisture estimates collected in Sodankylä during summer 2012. Time series (left column panels) and scatter plots (right column panels) of soil moisture measured in $0-5 \mathrm{~cm}$ depth from the "HA Open 1" network station with low organic mineral soil (top row panels) as well as at the "UG Forest 1" network station with a pronounced organic surface layer (bottom row panels) are depicted. In the case of "UG Forest 1", soil moisture data sets using both default calibrations (black) and newly derived fits (red) are presented. For the ThetaProbe average of five readings, respective standard deviations are displayed as error bars in the time series (left column), and hourly rainfall intensities ( $\left.\mathrm{R} \_1 \mathrm{H}\right)$ are also plotted along (black bars). Details on the applied calibration functions as well as corresponding statistics are given in Table 7 .

The measurements of the two sensor types at the "HA Open 1" site (top row panels) are in very good agreement using the default calibrations (black signatures) for mineral soils. In contrast, applying the most appropriate default calibrations available for the two sensors at the "UG Forest 1" site (bottom row), a pronounced difference in soil moisture content is observed. Thereby the ThetaProbe soil moisture estimates are much wetter and their dynamic range much larger compared to the Decagon 5TE sensor. When using our fit functions derived for organic material (third-order polynomial for ThetaProbe and natural logarithm for Decagon 5TE, red signatures), the agreement becomes much better with significantly decreased RMSD and bias. Also, it now nicely stands out that the mean soil moisture level of the sandy mineral soil (top row panels) is lower but with larger temporal 
Table 5. Statistics for manufacturer's default calibration curves and functions fitted through the data measured in organic layers $(\mathrm{SOM}>30 \%)$ as listed in Table 4 for Decagon 5TE $\left(\theta=\right.$ fct. $\left.\left(\varepsilon_{\mathrm{a}}\right)\right)$ and Delta-T ThetaProbe $\left(\theta=\right.$ fct. $\left(\varepsilon_{\mathrm{a}}\right)$ and $\theta=$ fct. (voltage)), respectively: $N$ is the number of sampling points, $R$ is Pearson's correlation coefficient, RMSD is bias-corrected root mean square deviation, BIAS is bias, $\theta$ is volumetric moisture content, $\varepsilon_{\mathrm{a}}$ is apparent relative permittivity.

\begin{tabular}{lllcccl}
\hline Sensor type & $\theta=$ fct. $(x)$ & Function type & $N$ & $R$ & RMSD & BIAS \\
\hline Decagon ECH2O 5TE & $\varepsilon_{\mathrm{a}}$ & Default mineral & 50 & 0.92 & 0.077 & 0.127 \\
& & Fit (third-order polynomial) & 50 & 0.92 & 0.068 & $1.17 \times 10^{-17}$ \\
& & Fit (power) & 50 & 0.92 & 0.070 & $-4.82 \times 10^{-16}$ \\
& & Fit (natural logarithm) & 50 & 0.92 & 0.070 & $3.68 \times 10^{-9}$ \\
& & Fit (square root) & 50 & 0.91 & 0.071 & $-2.42 \times 10^{-12}$ \\
\hline Delta-T ThetaProbe & \multirow{2}{*}{$\mathrm{a}$} & Default mineral & 70 & 0.84 & 0.110 & -0.004 \\
ML2x & & Default organic & 70 & 0.84 & 0.110 & -0.080 \\
& \multirow{2}{*}{ Voltage } & Fit (first-order polynomial) & 70 & 0.87 & 0.102 & 0.004 \\
& & Default mineral & 70 & 0.84 & 0.110 & -0.004 \\
& & Default organic & 70 & 0.84 & 0.110 & -0.078 \\
& & Fit (third-order polynomial) & 70 & 0.87 & 0.100 & 0.001 \\
\hline
\end{tabular}
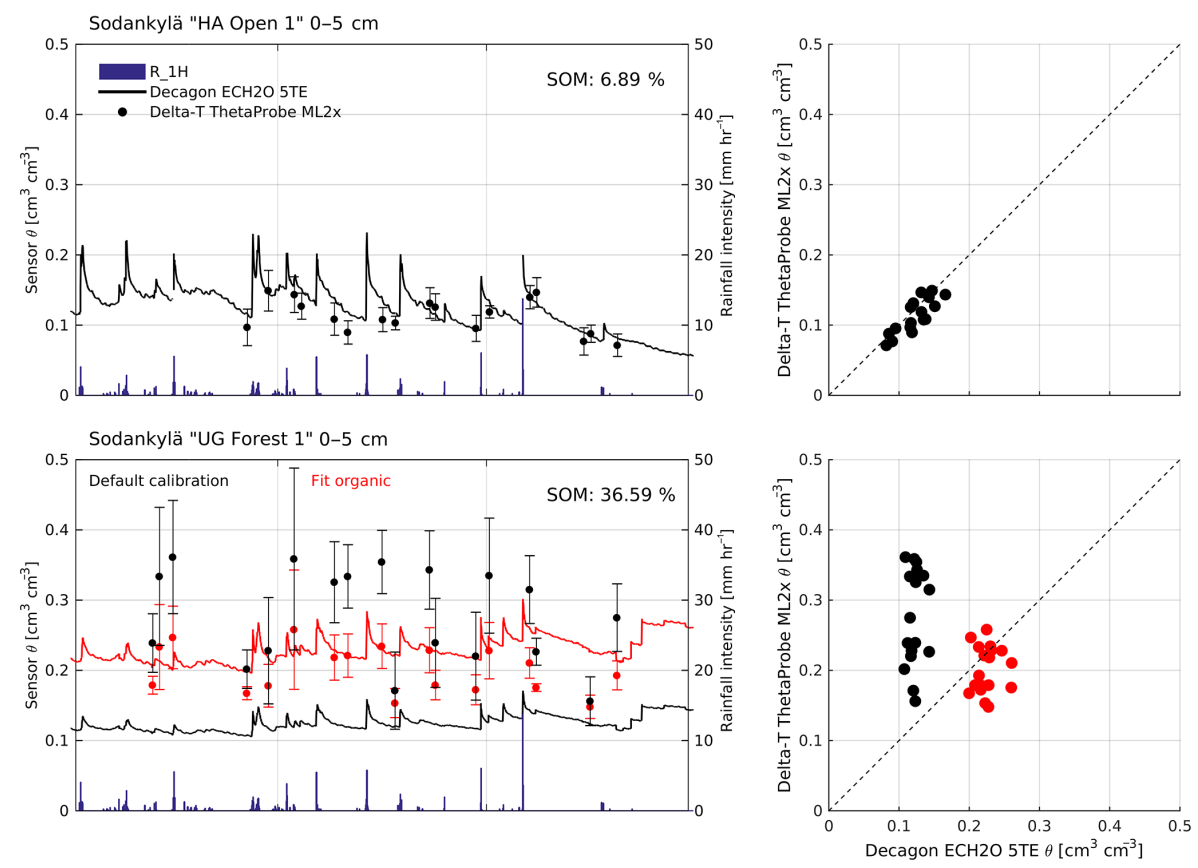

Figure 5. Time series (left column panels) and scatter plots (right panels) for the soil moisture $(\theta)$ measured at $0-5 \mathrm{~cm}$ depth by ThetaProbe (average of five readings with standard deviations as error bars) and Decagon 5TE sensors at the Sodankylä "HA Open 1" (upper row panels: low organic mineral soil, $\mathrm{SOM}=6.89 \%$ ) and "UG Forest 1" (lower row panels: organic substrate, $\mathrm{SOM}=36.59 \%$ ) network stations during summer 2012. Hourly rainfall intensities (R_1H) from Tähtelä are plotted along. Details on the applied calibration functions (default in black and newly derived in red) as well as corresponding statistics are given in Table 7.

dynamics compared to the organic surface layer (bottom row panels). This behavior is expected due to low and high water retention capacities of the two materials, respectively.

Only the correlation between the two sensors remains still low in the case of the organic layer, especially caused by the observed scatter in the ThetaProbe data obtained by a handheld application with constantly changed sensor locations. This scatter is in similar range with the data variability pre- sented by Kurum et al. (2012), and significantly larger than observed in the mineral soil, both in terms of daily standard deviations of the five probe readings (error bars) and day-today variations. As already discussed in Sect. 5.3, the more pronounced small-scale variabilities in the organic substrate are a consequence of more complex structure compared to the more homogeneously distributed sandy soil encountered at the "HA Open 1" site, possibly intensified by compaction 
Table 6. Statistics for the applied petrophysical and empirical relationships for organic soil layers extracted from the literature as well as for manufacturer's default calibration curves and our best fits (as presented in Fig. 4). $N$ is the number of sampling points, $R$ is Pearson's correlation coefficient, RMSD is bias-corrected root mean square deviation, BIAS is bias, $\theta$ is volumetric moisture content, $\varepsilon_{\mathrm{a}}$ is apparent relative permittivity.

\begin{tabular}{|c|c|c|c|c|c|c|c|}
\hline Sensor type & $\theta=$ fct. $(x)$ & Sensor type original study & Source & $N$ & $R$ & RMSD & BIAS \\
\hline \multirow[t]{10}{*}{ Decagon ECH2O 5TE } & \multirow{10}{*}{$\varepsilon_{\mathrm{a}}$} & - & Fit (Natural logarithm) & 50 & 0.92 & 0.070 & $3.68 \times 10^{-9}$ \\
\hline & & Decagon ECH2O 5TE & Vaz et al. (2013) & 50 & 0.91 & 0.075 & 0.003 \\
\hline & & \multirow[t]{8}{*}{ TDR } & Roth et al. (1992) & 50 & 0.91 & 0.072 & 0.084 \\
\hline & & & Yoshikawa et al. (2004) (living org.) & 50 & 0.91 & 0.077 & 0.133 \\
\hline & & & Pepin et al. (1992) & 50 & 0.90 & 0.077 & 0.032 \\
\hline & & & Pumpanen and Ilvesniemi (2005) & 50 & 0.91 & 0.086 & 0.077 \\
\hline & & & Malicki et al. (1996) (bulk density $=0.1$ ) & 50 & 0.91 & 0.071 & -0.013 \\
\hline & & & Kellner and Lundin (2001) & 50 & 0.91 & 0.071 & -0.012 \\
\hline & & & Schaap et al. (1996) & 50 & 0.92 & 0.071 & -0.008 \\
\hline & & & Paquet et al. (1993) & 50 & 0.92 & 0.069 & -0.018 \\
\hline Delta-T ThetaProbe & $\varepsilon_{\mathrm{a}}$ & - & Fit (first-order polynomial) & 70 & 0.87 & 0.102 & 0.004 \\
\hline \multirow[t]{6}{*}{ ML2x } & & Delta-T ThetaProbe ML2x & Yoshikawa et al. (2004) (living org.) & 70 & 0.87 & 0.111 & 0.063 \\
\hline & & & Kargas and Kerkides (2008) & 70 & 0.84 & 0.123 & -0.169 \\
\hline & \multirow{4}{*}{ Voltage } & - & Fit (third-order polynomial) & 70 & 0.87 & 0.100 & 0.001 \\
\hline & & Delta-T ThetaProbe ML2x & Vaz et al. (2013) & 70 & 0.81 & 0.124 & -0.008 \\
\hline & & & Nemali et al. (2007) & 70 & 0.70 & 0.154 & 0.045 \\
\hline & & & $\begin{array}{l}\text { Kurum et al. }(2012) \text { (OL layer, } \\
\text { bulk density }=0.1)\end{array}$ & 70 & 0.80 & 0.124 & -0.129 \\
\hline
\end{tabular}

Table 7. Statistics for comparison of $0-5 \mathrm{~cm}$ volumetric moisture content $(\theta)$ estimates by means of Delta-T ThetaProbe and Decagon 5TE sensors at the Sodankylä "HA Open 1" (low organic mineral soil, SOM=6.89\%) and "UG Forest 1" (organic substrate, SOM=36.59\%) network stations during summer 2012, using calibration functions as indicated below. $N$ is the number of sampling points, $R$ is Pearson's correlation coefficient, RMSD is bias-corrected root mean square deviation, and BIAS is bias.

\begin{tabular}{llllllr}
\hline Site & \multicolumn{2}{c}{ Calibration function type } & $N$ & $R$ & RMSD & BIAS \\
\cline { 2 - 6 } & Delta-T ThetaProbe ML2x & Decagon ECH2O 5TE & & & & \\
\hline Sodankylä "HA Open 1" & Default mineral & Default mineral & 17 & 0.82 & 0.0142 & -0.0097 \\
Sodankylä "UG Forest 1" & Default organic & Default mineral & 18 & 0.12 & 0.0663 & 0.1566 \\
& Fit third-order polyorganic & Fit natural log organic & 18 & 0.06 & 0.0355 & -0.0238 \\
\hline
\end{tabular}

effects originating from the susceptible sensor. However, irrespectively the cause, the newly derived fit functions clearly outperform the default calibration functions at the "UG Forest 1" site.

We suggest that these new ThetaProbe calibrations for organic substrates should only be used for the probe application method they were derived from, i.e., handheld. In that case, even if soil moisture data acquired using the ThetaProbe in organic-rich soils should be interpreted carefully, the sensor used together with the here-proposed calibration functions proves robust and of value for the acquisition of quick and instantaneous information about the moisture content for large areas as, for example, practiced in airborne campaigns for satellite cal/val purposes (e.g., Cosh et al., 2005; Bircher et al, 2012b). There, averaging over larger sets of readings will further balance out differing compaction and heterogeneity effects in individual readings - compared to our example where the mean of only five ThetaProbe readings was taken for comparison with point station data.
Finally, comparison with hourly rainfall intensities shows that the Decagon 5TE soil moisture time series estimated using the newly developed calibration function also well reflect the precipitation pattern, demonstrating the sensor's ability to yield reliable soil moisture time series in both mineral and organic substrates. Based on the very satisfying overall performance of the derived natural log fit function, it was applied in the calculation of the Decagon 5TE network soil moisture from organic surface layers at the Sodankylä and HOBE study sites to improve the quality in the data gathered so far.

\section{Summary and conclusions}

At both the Finnish Meteorological Institute's Arctic Research Center (FMI-ARC) in Sodankylä and the study site of the Danish Center for Hydrology (HOBE), soil moisture is a key research topic. With the purpose of serving coarseresolution satellite remote sensing and land surface modeling studies, Decagon 5TE sensors are applied in permanent soil 
moisture networks while ThetaProbes are used for hand-held soil moisture measurement campaigns. Because both locations are characterized by organic-rich soils, a joined effort aimed at calibrating these two electromagnetic sensor types for organic surface layers with SOM contents above $30 \%$. While some ThetaProbe calibration efforts for organic soil horizons are present in the literature, for the Decagon 5TE sensor such a calibration function has only been reported for an artificial organic material measured throughout a limited water content range (Vaz et al., 2013). The objective of the here-presented study was to provide generic and widely applicable calibrations for both studied sensor types holding for a variety of natural organic substrates as encountered within the large areas under consideration. Necessarily, these functions hold a decreased degree of detail and might lack high accuracy, but will clearly outperform standard calibration functions reported by the manufacturers. The used soil samples originated from different locations in northern regions, mainly including the Sodankylä and HOBE network areas, spanning a wide range of different humus types. We believe that a reliable calibration approach has been worked out with (1) the same measurement and calibration protocol followed at all sites, (2) comparison of data from organic and mineral horizons including laboratory and field measurements, and (3) consideration of material-specific characteristics such as shrinkage and charring during drying.

For both the Decagon 5TE sensor and the ThetaProbe, the variety of organic samples showed a consistent sensor output-moisture content response. Likewise, this was the case when the laboratory experiment was repeated in the field under less disturbed conditions, demonstrating independence of the acquired data from the chosen experimental setup. Deviating sensor outputs for measurements conducted in organic horizons ( $>30 \% \mathrm{SOM}$ ) compared to mineral layers were clearly identified (see Table 1 for SOM contents). For the mineral soil layers with a soil organic matter content below $10 \%$, the validity of the respective manufacturer calibrations could be demonstrated in the case of both Decagon 5TE and ThetaProbe. For the mineral samples with a SOM content exceeding $10 \%$, the ThetaProbe data showed a behavior comparable to the measurements in mineral soils with SOM fraction $<10 \%$, while in the respective Decagon 5TE data a clear tendency towards decreased $\varepsilon_{\mathrm{a}}$ at a given moisture content could be observed. This effect became even more pronounced for the measurements in the organic horizons though it seemed to level off, meaning that beyond a SOM content of $30 \%$ no further $\varepsilon_{\mathrm{a}}$ decrease with augmenting soil organic matter was clearly visible. This behavior is in accordance with previous TDR studies (e.g., Topp et al., 1980; Roth et al., 1992; Paquet et al., 1993; Kellner and Lundin, 2001; Jones et al., 2002), and explicable by an increased bound water fraction in porous organic matter with larger specific surface area compared to the underlying sandy mineral soils. In contrast, the ThetaProbe data acquired from the organic soil layers showed a closer match with the manufac- turer's functions derived for mineral and organic substrates, though with more pronounced curvature.

Based on the above results, for all data measured in the organic horizons, one calibration function was derived per sensor type. A natural logarithm and first-order polynomial were fitted through the $\varepsilon_{\mathrm{a}}$ and soil moisture couples for the Decagon 5TE and ThetaProbe sensors, respectively. In the case of the ThetaProbe, a third-order polynomial was selected for the corresponding pairs of voltage and soil moisture.

The fact that there was no clear difference in the data obtained from the different sampling sites spanning a variety of humus types and acquired by different users strengthens confidence that the derived calibration functions are not only site specific but can be applied over a wide range of locations and organic materials of differing characteristics and SOM contents. This renders them highly suitable to support large-scale remote sensing and land surface modeling studies.

In the case of the Decagon 5TE sensor, the reliability of the proposed calibration function is further underlined by the fact that it obeys basic physical principles (i.e., increased bound water fraction in the case of organic material), the good agreement with the Decagon 5TE calibration law for a plant potting mix reported by Vaz et al. (2013), as well as by comparable curve shapes as presented in respective TDR calibration studies. Meanwhile, for the ThetaProbe data, such a clear consistency between measurements, fitted functions, and theory is lacking, which is further reflected in the nonuniform behavior of earlier derived calibration laws for organic material reported by other authors.

Comparison of independent Decagon 5TE and ThetaProbe soil moisture time series using default calibrations (not used for the calibration) yield good agreement for the Sodankylä "HA Open 1" network stations' mineral surface layer. In the case of the "UG Forest 1" network stations' organic surface horizon reasonable accordance could only be achieved when using our fit functions derived for organic material (natural logarithm for Decagon 5TE and third-order polynomial for ThetaProbe). The latter significantly improved RMSD and bias so that average soil moisture levels coincided. Only the correlation between the two sensors in the organic layer stayed low, especially caused by the observed scatter in the ThetaProbe data. This is mostly a consequence of the handheld application with constantly changed sensor locations, leading to more pronounced short range variabilities in the data from a highly heterogeneous material, possibly intensified by compaction effects originating from the susceptible sensor. However, irrespectively the cause, the newly derived calibration fit functions clearly outperform the default functions at the "UG Forest 1" site.

We suggest that the newly derived ThetaProbe calibration fit functions for organic substrates should only be used together with the probe application it was derived from, i.e., handheld. In that case, the functions prove robust and of value for the acquisition of quick and instantaneous infor- 
mation about the moisture content for large areas, where averaging over larger sets of readings will balance out differing compaction and heterogeneity effects in individual readings.

Finally, field data from Sodankylä demonstrate the ability of the Decagon 5TE sensor to reflect precipitation patterns in mineral soils as well as organic horizons. Based on the very satisfying overall performance of the derived natural log fit function it was applied in the calculation of soil moisture from organic surface layers at the Sodankylä and HOBE network sites to improve the quality in the so far gathered data.

Though the here-proposed calibration functions are derived based on samples collected in the higher northern latitudes, they should also be applicable to soil moisture measurements in similar media encountered in other regions of the world. If more data were collected in the future, a Decagon 5TE calibration law for mineral horizons as a function of SOM content could possibly be derived.

Acknowledgements. Financial support for conducting this research by the following institutions is gratefully acknowledged: European Space Agency (Support to Science Element - Changing Earth Science Network and Expert Support Laboratory); Centre National d'Etudes Spatiales (Terre, Océans, Surfaces Continentales, Atmosphère Programme, TOSCA), France; Villum Foundation (Hydrological Observatory, HOBE), Denmark; University of Copenhagen (Department of Geosciences and Resource Management), Denmark; Finnish Meteorological Institute; German Federal Ministry of Education and Research (Terrestrial Environmental Observatories, TERENO); Transnational Access to Research Infrastructures activity in the 7th Framework Programme of the EC under the ExpeER project.

Edited by: C. Ménard

\section{References}

Albergel, C., de Rosnay, P., Gruhier, C., Muñoz Sabater, J., Hasenauer, S., Isaksen, L., Kerr, Y., and Wagner, W.: Evaluation of remotely sensed and modelled soil moisture products using global ground-based in-situ observations, Remote Sens. Environ., 118, 215-226, 2012.

Andreasen, M., Jensen, K. H., Zreda, M., Desilets, D., Bogena, H., and Looms, M. C.: A method to obtain comparable measured and modeled cosmic-ray neutron intensities, Water Resour. Res., in revision, 2016.

Assouline, S., Narkis, K., Tyler, S. W., Lunati, I., Parlange, M. B., and Selker, J. S.: On the Diurnal Soil Water Content Dynamics during Evaporation using Dielectric Methods, Vadose Zone J., 9, 709-718, 2010.

Baggaley, N., Mayr, T., and Bellamy, P.: Identification of key soil and terrain properties that influence the spatial variability of soil moisture throughout the growing season, Soil Use Manage., 25, 262-273, 2009.

Bircher, S., Skou, N., Jensen, K. H., Walker, J. P., and Rasmussen, L.: A soil moisture and temperature network for SMOS valida- tion in Western Denmark, Hydrol. Earth Syst. Sci., 16, 14451463, doi:10.5194/hess-16-1445-2012, 2012a.

Bircher, S., Balling, J. E., Skou, N., and Kerr, Y.: Validation of SMOS brightness temperatures during the HOBE airborne campaign, Western Denmark, IEEE T. Geosci. Remote, 50, 1468 $1482,2012 b$

Blonquist, J. M., Jones, S. B., and Robinson, D. A.: Standardizing Characterization of Electromagnetic Water Content Sensors: Part 2. Evaluation of Seven Sensing Systems, Vadose Zone J., 4, 1059-1069, 2005.

Bogena, H. R., Huisman, J.A., Oberdorster, C., and Vereecken, H.: Evaluation of a low-cost soil water content sensor for wireless network applications, J. Hydrol., 344, 32-42, 2007.

Börner, T., Johnson, M. G., Rygiewicz, P. T., Tingey, D. T., and Jarrell, G. D.: A two-probe method for measuring water content of thin forest floor litter layers using time domain reflectometry, Soil Technol., 9, 199-207, 1996.

Broll, G., Brauckmann, H.-J., Overesch, M., Junge, B., Erber, C., Milbert, G., Baize, D., and Nachtergaele, F.: Topsoil characterization - recommendations for revisions and expansion of the FAO-Draft (1998) with emphasis on humus forms and biological features, J. Plant Nutr. Soil Sci., 169, 453-461, 2006.

Cosh, M. H., Jackson, T. J., Bindlish, R., Famiglietti, J. S., and Ryu, D.: Calibration of an impedance probe for estimation of surface soil water content over large regions, J. Hydrol., 311, 49-58, 2005.

Czarnomski, N. M., Moore, G. W., Pypker, T. G., Licata, J., and Bond, B. J.: Precision and accuracy of three alternative instruments for measuring soil water content in two forest soils of the Pacific Northwest, Can. J. Forest Res., 35, 1867-1876, 2005.

Decagon Devices Inc.: ECH2O soil moisture sensor, Operator's manual for model 5TE, Decagon Devices Inc., Pullman, WA, USA, 2014

Delta-T Devices Ltd.: ThetaProbe Soil Moisture Sensor Type ML2x User Manual, ML2x-UM-1.21, Delta-T Devices Ltd., Burwell, Cambridge, GB, 1999.

Dirksen, C. and Dasberg, S.: Improved calibration of time domain reflectometry soil water content measurements, Soil Sci. Soc. Am. J., 57, 660-667, 1993.

Dorigo, W. A., Wagner, W., Hohensinn, R., Hahn, S., Paulik, C., Xaver, A., Gruber, A., Drusch, M., Mecklenburg, S., van Oevelen, P., Robock, A., and Jackson, T.: The International Soil Moisture Network: a data hosting facility for global in situ soil moisture measurements, Hydrol. Earth Syst. Sci., 15, 1675-1698, doi:10.5194/hess-15-1675-2011, 2011.

Evett, S. R., Tolk, J. A., and Howell, T. A.: Soil Profile Water Content Determination: Sensor Accuracy, Axial Response, Calibration, Temperature Dependence, and Precision, Vadose Zone J., 5, 894-907, 2006.

Famiglietti, J. S., Ryu, D., Berg, A. A., Rodell, M., and Jackson T. J.: Field observations of soil moisture variability across scales, Water Resour. Res., 44, W01423, doi:10.1029/2006WR005804, 2008.

Ganjegunte, G. K., Sheng, Z., and Clark, J. A.: Evaluating the accuracy of soil water sensors for irrigation scheduling to conserve freshwater, Appl. Water Sci., 2, 119-125, 2012.

Gaskin, G. J. and Miller, J. D.: Measurement of soil water content using a simplified impedance measuring technique, J. Agr. Eng. Res., 63, 153-159, 1996. 
Hansen, J., Sato, M., Ruedy, R., Lo, K., Lea, D. W., and MedinaElizade, M.: Global temperature change, P. Natl. Acad. Sci., 103, 14288-14293, 2006.

Herkelrath, W. N., Hamburg, S. P., and Murphy, F.: Automatic, realtime monitoring of soil moisture in a remote field area with time domain reflectometry, Water Resour. Res., 27, 857-864, 1991.

Ikonen, J., Vehviläinen, J., Rautiainen, K., Smolander, T., Lemmetyinen, J., Bircher, S., and Pulliainen, J.: The Sodankylä in situ soil moisture observation network: an example application of ESA CCI soil moisture product evaluation, Geosci. Instrum. Method. Data Syst., 5, 95-108, doi:10.5194/gi-5-95-2016, 2016.

IPCC 2007 Climate Change: The Physical Science Basis, in: Contribution of Working Group I to the Fourth Assessment Report of the Intergovernmental Panel on Climate Change, edited by: Solomon, S., Qin, D., Manning, M., Chen, Z., Marquis, M., Averyt, K. B., Tignor, M., and Miller, H. L., Cambridge University Press, Cambridge, UK and New York, NY, USA, 2007.

Jensen, K. and Illangasekare, T.: HOBE: A hydrological observatory, Vadose Zone J., 10, 1-7, 2011.

Jonard, F., Demontoux, F., Bircher, S., Razafindratsima, S., Schwank, M., Weihermüller, L., Lambot, S., Wigneron, J.-P., Kerr, Y. H., and Vereecken, H.: Electromagnetic characterization of organic-rich soils at the microwave L-band with groundpenetrating radar, radiometry and laboratory measurements, in: proceedings of the 15th International Conference on Ground Penetrating Radar, 30 June-4 July 2014, Brussels, Belgium, 202207, 2014.

Jones, S., Wraith, J. M., and Or, D.: Time domain reflectometry measurement principles and applications, Hydrol. Process., 16, 141-153, 2002.

Kang, S. W., Seo, S. G., Lee, G. P., and Pak, C. H.: Estimation of soil moisture curves of mixed media using a dielectric moisture sensor, Horticult. Environ. Biotechnol., 51, 28-32, 2010.

Kargas, G. and Kerkides, P. : Water content determination in mineral and organic porous media by ML2 Theta Probe, Irrig. Drain., 57, 435-449, 2008.

Kelleners, T. J., Seyfried, M. S., Blonquist Jr., J. M., Bilskie, J., and Chandler, D. G.: Improved Interpretation of Water Content Reflectometer Measurements in Soils, Soil Sci. Soc. Am. J., 69, 1684-1690, 2005.

Kellner, E. and Lundin, L.-C.: Calibration of time domain reflectometry for water content in peat soil, Nord. Hydrol., 32, 315332, 2001.

Kizito, F., Campbell, C. S. Campbell, G. S., Cobos, D. R., Teare, B. L., Carter, B., and Hopmans, J. W.: Frequency, electrical conductivity and temperature analysis of low-cost capacitance soil moisture sensor, J. Hydrol., 352, 367-378, 2008.

Kurum, M., O’Neill, P. E., Lang, R. H., Cosh, M. H., Joseph, A. T., and Jackson, T. J.: Impact of conifer forest litter on microwave emission at L-band, IEEE T. Geosci. Remote, 50, 1071-1084, 2012.

Li, H., Parent, L. E., Karam, A., and Tremblay, C.: Potential of Sphagnum peat for improving soil organic matter, water holding capacity, bulk density and potato yield in a sandy soil, Plant Soil, 265, 355-365, 2004.

Lopez-Vicente, M., Navas, A., and Machin, J.: Effect of physiographic conditions on the spatial variation of seasonal topsoil moistuer in Mediterranean soils, Aust. J. Soil Res., 47, 498-507, 2009.
Malicki, M. A., Plagge, R., and Roth, C. H.: Improving the calibration of dielectric TDR soil moisture determination taking into account the solid soil, Eur. J. Soil Sci., 47, 357-366, 1996.

Mätzler, C.: Thermal Microwave Radiation: Applications for Remote Sensing, in: Chapter 5.7 - Dielectric properties of heterogeneous media edited by: Mätzler, C., Rosenkranz, P. W., Battaglia, A., and Wigneron, J. P., IET Electromagnetic Waves Series, 52, Institute of Engineering and Technology, Stevenage, UK, 2006.

Mittelbach, H., Lehner, I., and Seneviratne, S. I.: Comparison of four soil moisture sensor types under field conditions in Switzerland, J. Hydrol., 430-431, 39-49, 2012.

Myllys, M. and Simojoki, A.: Calibration of time domain reflectometry (TDR) for soil moisture measurements in cultivated peat soils, Suo, 47, 1-6, 1996.

Nagare, R. M., Schincariol, A., Quinton, W. L., and Hayashi, M.: Laboratory calibration of time domain reflectometry to determine moisture content in undisturbed peat samples, Eur. J. Soil Sci., 62, 505-515, 2011.

Nemali, K. S., Montesano, F., Dove, S. K., and van Iersel, M. W.: Calibration and performance of moisture sensors in soilless substrates: ECH2O and Theta Probes, Scient. Horticult., 112, 227234, 2007.

O'Kelly, B.: Accurate determination of moisture content of organic soils using the oven drying method, Dry. Technol., 22, 17671776, 2004.

Or, D., and Wraith, J. M.: Temperature effects on soil bulk dielectric permittivity measured by time domain reflectometry: A physical model, Water Resour. Res., 35, 371-383, 1999.

Overduin, P. P., Yoshikawa, K., Kane, D. L., and Harden, J. W.: Comparing electronic probes for volumetric water content of low-density feathermoss, Sensor Rev., 25, 225-221, 2005.

Paquet, J. M., Caron, J., and Banton, O.: In situ determination of the water desorption characteristics of peat substrates, Can. J. Soil Sci., 73, 329-339, 1993.

Pepin, S., Plamondon, A. P., and Stein, J.: Peat water content measurement using time domain reflectometry, Can. J. Forest Res., 22, 534-540, 1992.

Pumpanen, J. and Ilvesniemi, H.: Calibration of time domain reflectometry for forest soil humus layers, Boreal Environ. Res., 10, 589-595, 2005.

Rautiainen, K., Lemmetyinen, J., Pulliainen, J., Vehviläinen, J., Drusch, M., Kontu, A., Kainulainen, J., and Seppänen, J.: L-band radiometer observations of soil processes in boreal and subarctic environments, IEEE T. Geosci. Remote, 50, 1483-1497, 2012.

Rautiainen K., Lemmetyinen, J., Schwank, M., Kontu, A., Ménard, C. B., Mätzler, C., Drusch, M., Wiesmann, A., Ikonen, J., and Pulliainen, J.: Detection of soil freezing from L-band passive microwave observations, Remote Sens. Environ., 147, 206-218, 2014.

Reichle, R. H., Koster, R. D., Sarith, P. L, Mahanama, P. P., Njoku, E. G., and Owe, M.: Comparison and assimilation of global soil moisture retrievals from the Advanced Microwave Scanning Radiometer for the Earth Observing System (AMSR-E) and the Scanning Multichannel Microwave Radiometer (SMMR), J. Geophys. Res.-Atmos., 112, D09108, doi:10.1029/2006JD008033, 2007.

Robinson, D. A., Gardner, C. M. K., and Cooper, J. D.: Measurement of relative permittivity in sandy soils using TDR, capaci- 
tance and theta probes: comparison, including the effects of bulk soil electrical conductivity, J. Hydrol., 223, 198-211, 1999.

Robinson, D. A., Jones, S. B., Wraith, J. M., Or, D., and Friedman, S. P.: A Review of Advances in Dielectric and Electrical Conductivity Measurement in Soils Using Time Domain Reflectometry, Vadose Zone J., 2, 444-475, 2003.

Robinson, D. A., Campbell, C. S., Hopmans, J. W., Hornbuckle, B. K., Jones, S. B., Knight, R., Ogden, F., Selker, J., and Wendroth, O.: Soil Moisture Measurement for Ecological and Hydrological Watershed-Scale Observatories: A Review, Vadose Zone J., 7, 358-389, 2008.

Rosenbaum, U., Huisman, J. A. Weuthen, A., Vereecken, H., and Bogena, H. R.: Sensor-to-sensor Variability of the ECH2O EC5, TE, and 5TE Sensors in Dielectric Liquids, Vadose Zone J., 9, 181-186, 2010.

Rosenbaum, U., Huisman, J. A., Vrba, J., Vereecken, H., and Bogena, H. R.: Correction of temperature and electrical conductivity effects on dielectric permittivity measurements with ECH2O sensors, Vadose Zone J., 10, 582-593, 2011.

Roth, C. H., Malicki, M. A., and Plagge, R.: Empirical evaluation of the relationship between soil dielectric constant and volumetric water content as the basis for calibrating soil moisture measurements by TDR, J. Soil Sci., 43, 1-13, 1992.

Roth, K., Schulin, R., Flühler, H., and Attinger, W.: Calibration of Time Domain Reflectometry for Water Content Measurement Using a Composite Dielectric Approach, Water Resour. Res., 26, 2267-2273, 1990.

Saito, T., Fujimaki, H., Yasuda, H., and Inoue, M.: Empirical temperature calibration of capacitance probes to measure soil water, Soil Sci. Soc. Am. J., 73, 1931-1937, 2009.

Sakaki, T., Limsuwat, A., and Illangasekare, T.: A Simple Method for Calibrating Dielectric Soil Moisture. Sensors: Laboratory Validation in Sands, Vadose Zone J., 10, 526-531, 2011.

Schaap, M. G., de Lange, L., and Heimovaara, T. J.: TDR calibration of organic forest floor media, Soil Technology, 11, 205-217, 1996.

Shibchurn, A., Van Geel, P. J., and Kennedy, P. L.: Impact of density on the hydraulic properties of peat and the time domain reflectometry (TDR) moisture calibration curve, Can. Geotech. J., 42, 279-286, 2005.

Stokstad E.: Defrosting the carbon freezer of the north, Science, 304, 1618-1620, 2004.

Topp, G. C.: State of the art of measuring soil water content, Hydrol. Process., 17, 2993-2996, 2003.
Topp, G. C., Davis, J. L., and Annan, A. P.: Electromagnetic determination of soil water content: measurement in coaxial transmission lines, Water Resour. Res., 16, 574-582, 1980.

Varble, J. L. and Chavez, J. L.: Performance evaluation and calibration of soil water content and potential sensors for agricultural soils in eastern Colorado, Agr. Water Manage., 101, 93106, 2011.

Vasquez, V.: Profile Soil Water Content Measurements for Estimation of Groundwater Recharge in Different Land Uses, PhD Thesis, Aarhus University, Aarhus, Denmark, 2013.

Vasquez, V. and Thomsen, A.: Calibration of a capacitance probe for groundwater recharge modeling based on soil moisture dynamics, in: proceedings of the 1st International Conference and Exploratory Workshop on Soil Architecture and Physio-chemical Functions, 30 November-2 December 2010, Aarhus University Research Center Foulum, Aarhus, Denmark, 395-398, 2010.

Vaz, C. M. P., Jones, S., Meding, M., and Tuller, M.: Evaulation of standard calibration functions for eight electromagentic soil moisture sensors, Vadose Zone J., 12, 1-16, 2013.

Walker, J. P., Willgoose, G. R., and Kalma, J. D.: In situ measurement of soil moisture: a comparison of techniques, J. Hydrol., 293, 85-99, 2004.

Wang, J. and Schmugge, T.: An empirical model for the complex dielectric permittivity of soil as a function of water content, IEEE T. Geosci. Remote, 18, 288-295, 1980.

Western, A. W., Grayson, R. B., and Bloeschl, G.: Scaling of soil moisture: a hydrologic perspective, Annu. Rev. Earth Planet. Sci., 30, 149-180, 2002.

Yoshikawa, K., Overduin, P. P., and Harden, J. W.: Moisture content measurements of moss (sphagnum spp.) using commercial sensors, Permafrost Periglac. Process., 15, 309-318, 2004.

Yu, C., Warrick, A. W., and Conklin, M. H.: Derived functions of time domain reflectometry for soil moisture meaurement, Water Resour. Res., 35, 1789-1796, 1999.

Zanella, A., Jabiol, B., Ponge, J. F., Sartori, G., De Waal, R., Van Delft, B., Graefe, U., Cools, N., Katzensteiner, K., Hager, H., Englisch, M., Brethes, A., Broll, G., Gobat, J. M., Brun, J. J., Milbert, G., Kolb, E., Wolf, U., Frizzera, L., Galvan., P., Kolli, R., Baritz, R., Kemmers, R., Vacca, A., Serra, G., Banas, D., Garlato, A., Chersich, S., Klimo, E., and Langohr, R.: European Humus Forms Reference Base, http:// hal.archives-ouvertes.fr/hal-00541496/, last access: 28 November 2015, doi:10.13140/RG.2.1.1944.0801, 2011. 